\title{
Fotoğrafta Hareket Bağlamında Sinemagraf Tekniğinin Değerlendirilmesi
}

\author{
Ercan EROL*
}

özet

Sinemagraf, video veya fotoğraflardan elde edilen tek fotoğraf karesinde hareketli bölgelerin gizlenmesi veya görünmesi ile üretilir. Fotoğrafta hareketli görüntü arayışının güncel tekniği olan sinemagraf, fotoğraf ve sinema disiplinlerinin melez bir formu olarak, sayısal teknolojiler ile doğrudan ilişkilidir. Fotoğrafik ve sinematografik anlam düzeyleri, hareket, zaman, mekan, üç boyut temsilleri, ürettiği görme-izleme biçimi, değişken renk-leke-ışık değerleri ve tekniğin estetik dile dönüşümü ile çağdaş sanatın melez pratiğine uygun teknoloji temelli bir tekniktir. Çağdaş sanat formu olarak etkinliği, sanat kurum ve pratikleri, teknik sınırlılıklar, estetik diline, üretim, dağıım ve sunum kanallarının geliştirilmesine bağlıdır. Estetik dilinin görsel tasarımı destekleyen ve biçimlendiren yönleri ile sinemagraf, kitle iletişiminde etkin ve yeni bir görsel tasarım unsuru olarak mobil cihazların artışı ile üretim, dağıtım, sunum ve içerikte gelişim ve değişim gösterecektir. Bu makalede, fotoğrafta hareketli görüntü arayışının değişimi, sinemagraf tekniğinin fotoğrafta görüntü arayışına etkileri, sanat ve tasarım açısından estetik dönüşümleri, teorik ve pratik düzeyde analiz edilmektedir.

Anahtar Kelimeler: Çağdaş Sanat, Fotoğraf, Hareket, İnternet, Kompozisyon, Sinemagraf, Tasarım, Teknik.

\section{Evaluating of the Cinemagraph Technique in Context of Motion in Photography}

\section{Abstract}

A cinemagraph is created by hiding or displaying animated parts on a single photo frame produced from a video or photographs. Cinemagraph, the actual technique for the pursuit of animated images in photography; as a hybrid form of photography and cinema disciplines, is directly related to the digital technologies. With its photographic and cinematographic meaning levels; movement, time, space, 3D representations, see-watch form that it produced, various color-stain-shade values and suited for a hybrid practice in contemporary art with its transformation of the technique into aesthetics, cinemagraph is a technology-based technique. Its efficiency as a contemporary art form, artistic intituions and practices, technical limitations are dependent on the aesthetic language and on the development of the production, distribution and presentation channels. Cinemagraph, with its aspects supporting and shaping visual design of aesthetics, as a result of increasing number of mobile devices representing an efficient and innovative visual design of mass communication, will undergo changes and developments including production, distribution, presentation and content. In this article, the change of pursuit of animated image in photography, the effects of cinemagraph technique on this pursuit and its aesthetic transformations in terms of art and design are theoretically and practically analyzed.

Keywords: Contemporary Art, Photography, Motion, Internet, Composition, Cinemagraph, Design, Technique. 


\section{Giriş}

Sanayi Devrimi, bilim, sanat ve kültürel yaşamda birçok değişim ve dönüşü̈mü beraberinde getirmiştir. İlerleyen teknik ve estetik bileşenleri ile fotoğraf, değişim ve dönüşümlerin takipçisi, belgeleyicisi, aracı ve aynası olmuştur. Fotoğrafta hareket arayışlarının tarihsel kökenlerinde Sanayi Devrimi ile mekanikleşen, hızlanan hayatın yansıtılması söz konusudur. Bilgisayar, dijital fotoğraf makinesi ve sayısal iletişim teknolojilerinin icadı ile fotoğrafın üretim, sunum ve dağıtımı ilerlemeler gösterir. Günümüzün kitle iletişim araçlarında hızla yayılan sinemagraf tekniği, fotoğraf ve sinema-video arasındaki melez bir teknik olması itibari ile bu değişimlerin bir parçasıdır. Sinemagraf, video veya fotoğraflardan elde edilen tek fotoğraf karesinde hareketli bölgelerin gizlenmesi veya görülmesi ile üretilir. Harekete dayalı günümüz yaşamının teknik ve estetik dönüşümü fotoğrafta hareket arayışları ile görselleşir. Bu makalede, sinemagraf tekniği, fotoğrafta hareketli görüntü arayışı bağlamında incelenmiştir. Bunun yanı sıra, teknik, anlam ve estetik dönüşümü, çağdaş sanat ve tasarım bağlamında ele alınmıştır.

\section{Durağan Fotoğrafta Hareketin Tespiti ve Fotoğraf ile Hareketli Görüntü Arayışı}

Fotoğrafta hareket arayışları, durağan fotoğrafta hareketin tespiti ve fotoğraf ile hareketli görüntü olarak iki yaklaşımda ele alınabilir. Durağan fotoğrafta hareketin saptanması fotoğraf karesinde hareketin dondurularak tespit edilmesidir. Fotoğraf ile hareketli görüntü ise fotoğraf karesiyle hareket izlenimi oluşturulmasıdır. Tarihsel süreçte tekniğin ilerlemesine bağlı olarak iki durum birbirinden ayrılmakta veya birbirini tamamlamaktadır.

1888'de Ernst Mach, 1894'de A.M. Worthington, 1930'larda Harold Edgerton (elma ve iskambil kağıdını delen kurşun vb.) öncüllerinden daha yüksek enstantene değerleri ile durağan fotoğrafta hareketi tespit eder. 1880'li yıllarda 1/25 saniyeye düşen poz süreleri ile Eadweard Muybridge ve Étienne-Jules Marey fotoğraflarında insan ve hayvan hareketlerini inceler. Muybridge çalışmalarını ilerleterek 1894 yılında Zoopraxicope'u geliştirir (Fot. 1). 1859'de Henry Dumont'un geliştirdiği omniskop ${ }^{1}$, 1892'de Leon Bouly'nin geliştirdiği sinematograf ${ }^{2}$ ve Muybridge'in zoopraxiscope'unun temel prensibi fotoğrafların hareket ettirilerek hareket eden görüntü izlenimi üretmesidir. Dolayısı ile durağan fotoğrafta hareketi tespit etmek veya fotoğraf ile hareketli görüntü elde etmek birbirini kapsayan bir süreçtir. "Poz sürelerinin kısalmasıyla durağan görüntüde hareket tespit edildi, durağan görüntülerin hareket ettirilmesi ile de sinema tekniği bulundu" (Frizot, 1998: 256). Fotoğrafta hareketli görüntü arayışları Sanayi Devrimi ile gündelik hayatta belirgin hale gelen hız ve hareketin, bilimsel ve sanatsal araştırmaların yansıması olarak değerlendirilebilir. Fotoğraf bu yönüyle hareketi sabitleyen, ayn zamanda hareket ettirilen görüntüler ile Sinema tekniğinin bulunmasında etkili olan bir araç konumundadır. Bilgisayar, dijital fotoğraf makinesi ve sayısal iletişim teknolojilerin gelişmesi ile fotoğrafta hareketli görüntü arayışları biçim, içerik ve teknik olarak değişim gösterir. 1977 yılında Terry Welch tarafından oluşturulan gif dosya biçimi ile sayısal ekranda fotoğrafik hareketsiz görüntüler mümkün olur (Schiet, 2012: 6). 1987'de yayımlanan özel bir gif sürümü ile fotoğraflardan basit hareketli görüntüler elde edilir (Niewland, 2012: 6). Farklı sürelerde hareket ettirilen fotoğraflar tarihsel örneklerine benzer görüntüleri sayısal ekranda tek karede mümkün kılar. Gif dosya biçimi saniye başına düşen kare sayısı, içerikte fotoğrafların düzenlenebilmesi ve görüntülenebilmesi ile sayısal ekranlarda iletişim, eğlence vb. farklı amaçlarla kullanılır.

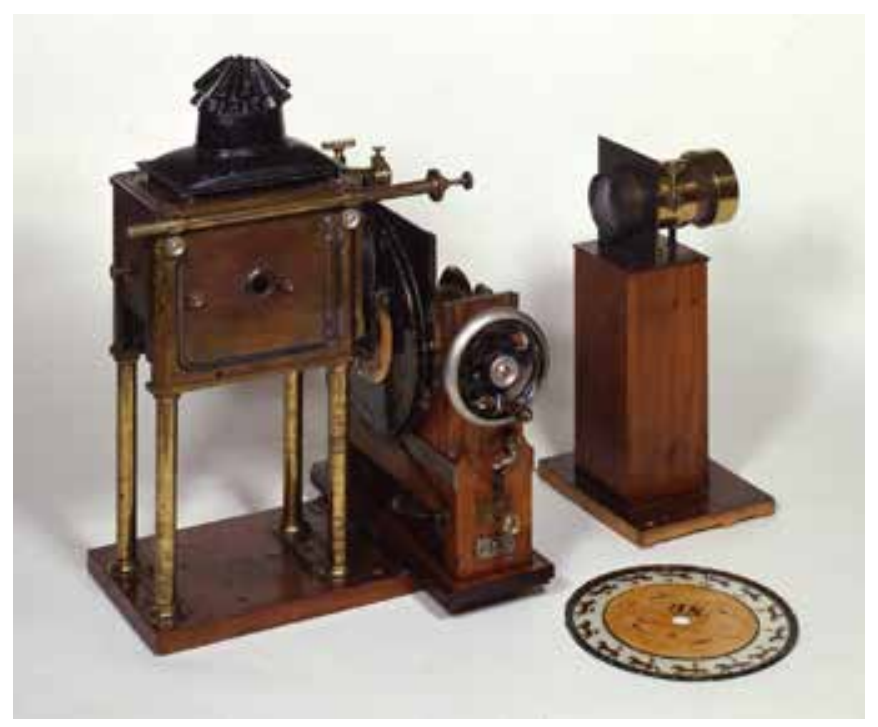

Fot. 1. Zoopraxiscope, Eadward Muybridge, 1894. 


\section{Sinemagrafta Teknik, Anlam ve Estetik İlişkisi}

Hareketli gif içerik ve teknik açısından değişime uğramakla birlikte 2011 yılında moda fotoğrafçısı Jamie Beck ve grafik tasarımcı Kevin Burg tarafından farklı bir amaçla kullanılır(Fot. 2) Kevin ve Jamie 2011 Şubat ayında Paris moda haftasında çekilen görüntülerden ürettikleri 'Les Tendrils' isimli hareketli gif'i Kevin Burg'un 'frommetoyou' adlı kişisel blog sitesi 'tumblr' hesabına ilk sinemagrafı yükler (Niewland, 2012: 3). Sinemagraf, video veya fotoğraftan elde edilen görüntülerin tek fotoğraf karesinde hareketli bölgelerin gizlenmesi veya görülmesi ile üretilir. Belli bir sürede video veya fotoğraf olarak kaydedilen görüntüler sayısal görüntü işleme programları (Adobe Premiere, Adobe Photoshop vb.) ile düzenlenerek gif dosya biçiminde sinemagraflar elde edilebilmektedir. Ayrıca, Rezervuar Köpekleri, 1984, Fight Club, Oldboy filmlerinin sahnelerinden elde edilen sinemagraflar mevcuttur (Mantel, 2012) (Fot. 3).

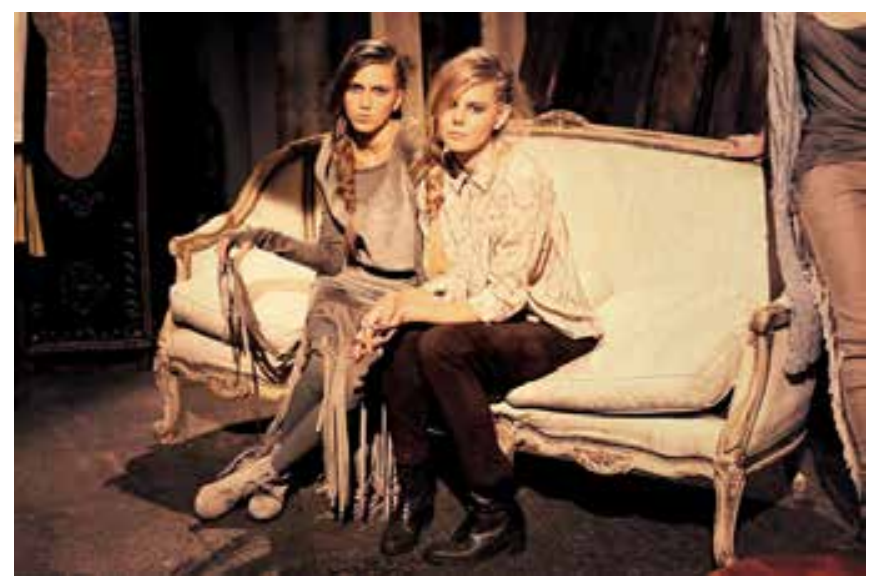

Fot. 2. Les Tendrils, Jamie Beck \& Kevin Burg, 2011.

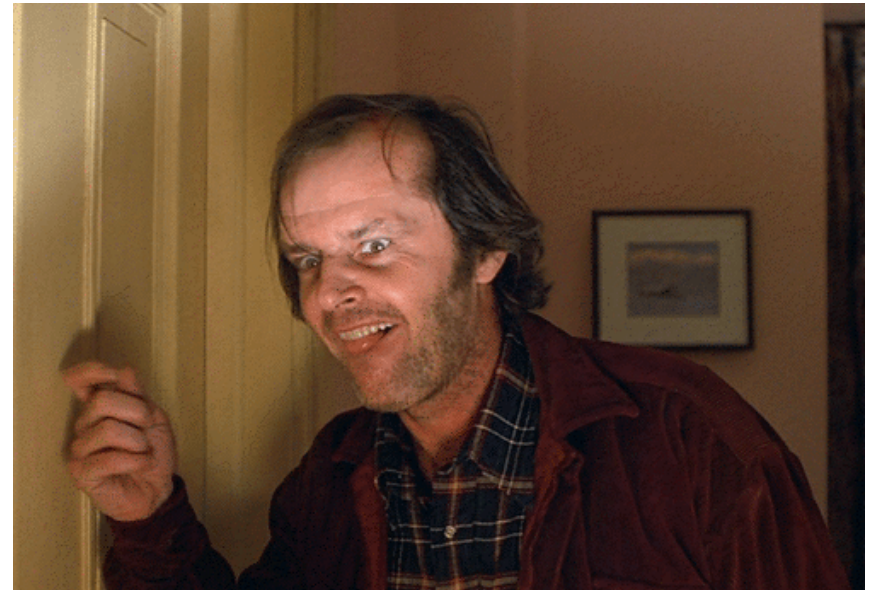

Fot. 3. Jack Nicholson-Shining, Gustav Mantel, 2012.
Tripod, sürekli ışık kaynağı ve paraflaş gibi yardımcı araçlar kullanılması, çekim bölgesinin iyi ışıklandırılması, seçilen hareketli bölgenin net ve temiz olması üretilen anlam ve nitelik açısından belirleyicidir (bkz. www.tumblr. com/blog/insfotog) Çekim aşamasında dikkat edilmesi gereken sonuç görüntüde hangi hareketlerin gösterilip, maskeleneceğidir. Birkaç kişinin olduğu sinemagrafta iki kişinin hareketi belirginse anlam bu kişilerin hareketlerine ve iletişimine göre oluşacaktır (Fot. 4).

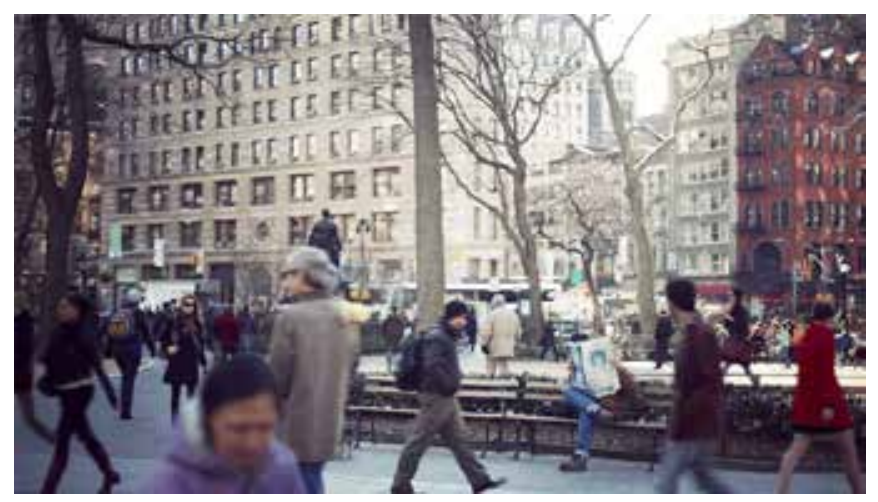

Fot. 4. There's always time for the paper, Jamie Beck \& Kevin Burg, 2011.

Örneğin kumaşlar, saçlar, yapraklar gibi hareketli olacağı düşünülen bir bölgeyi hareketsiz bırakmak fotoğrafik kompozisyonu, hareketleri maskelenmemiş bölgeler ise sinematografik etkiyi artıracaktır. Hareketli bölgenin önünde, arkasında başka hareketin olması, koyu renkler, az ışıklı çekimler gibi teknik sınırlılıklar, konu seçimi, hareketli bölge seçimi ve saniyedeki kare sayısı gibi konular fotoğrafçı için yeni bir görme biçimi oluşturmaktadır (Berger, 2005: 18). Fotoğrafçının yeni görme biçimi teknik sınırlılıklar ve nihai görüntüde elde edilmek istenene göre biçimlenen, konu seçiminde hareketi arayan bir deneyimdir. İzleyen için ise ilk sinemagraf şaşırtıcı bir etki bıraktıktan sonra hareketi gözle arama süreci başlamaktadır. Sinemagraf ile sinema-video ve fotoğrafta mevcut olmayan yeni bir izleme biçimi mümkün olmaktadır. İzleme biçimi ile sinemagrafın fotoğrafik ve sinematografik anlam düzeyleri oluşur. Hareketsiz bölgelerin kompozisyon unsurları, hareketli bölgenin ritm duygusu, renk-leke etkileri, ürettiği izleme biçimi ve sinematografik etkisi fiziki gerçekliğe gönderme yapar (Fot. 
5). Herhangi bir yemek sinemagrafında yükselen dumanlar ve yemeğin üzerindeki sıvıların hareketleri izleyende açlık duygusunu uyandırabilir. Bir ağaç sinemagrafında hareket eden yapraklar doğanın sakinliğine gönderme yapabilir.

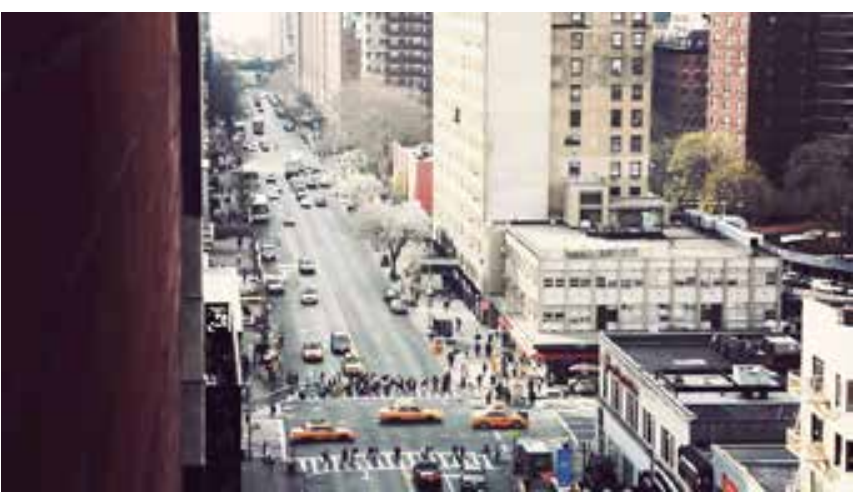

Fot. 5. Out My Chelsea Hotel Window, Jamie Beck \& Kevin Burg, 2011.

Sinemagrafta hareketin doğrultusu ve içeriği fiziki gerçekliğin üç boyutlu etkisini temsil etmektedir (Niewland, 2012: 19). Fotoğrafın iki boyutlu yüzeyinde renk, perspektif, ışık, ritim, doku değerleri ile temsil edilen üçüncü boyut hareket ile desteklenmektedir. Manovich'e göre (Manovich, 2001), yeni iletişim teknolojileri bilgileri organize ve koordine ederek zamanın kullanıcı üzerindeki etkisini artırır. Hareketli bölgenin gerçek hareket süresi ile sinemagraftaki farklıdır, değiştirilebilir. Zamanın izleyici üzerindeki etkisi kontrol edilebilir. Bunun yanında fotoğrafik kompozisyonu lekesellik ile destekleyen hareketli bölge, ritmi bozulmuş bir zaman temsiliyle sinematografik anlamı izleyenin zihninde oluşturur. "Sayısal teknolojilerle, fotoğraf makinaları ve yazılımlar teknik müdahale olanaklarını, karanlık odanın imkanlarının çok ötesinde gerçekleştirebilmekte, geliştirebilmektedir. Çünkü fotoğraf bir düzenlemedir, dijitalizimle bu düzene hakim olmak hiç olmadığı kadar kolaylaşmıştır. Fotoğraf sanatçısı da gittikçe artan oranda bu teknolojiyi kullanmakta, teknik dönüşüm estetik dönüşüme kuvvetli destek vermektedir."(Tümay, 2010: 20). Sinemagraf, sinema-video ve fotoğraf arasındaki bir teknik dönüşüm olmakla birlikte kendi estetiğini oluşturur. Dijital teknoloji sinemagrafın teknik dönüşümünü bir tasarım unsuruna dönüştürür. Sinemagraf, hareketsiz öğeler itibari ile fotoğraf; hareketli bölgeler, üretim biçimi ve sinematografik yapısı ile sinema-video alanındadır. Ürettiği izleme biçimi, ritmi, zamanın bozulması ve değiştirilmesi, hareket ve durağanlık ile üçüncü boyutun temsili gibi etkenlerden dolayı sinemagraf kendi estetik dilini teknik dahilinde oluşturur. Sinemagrafın estetik dili, fotoğrafın estetik diline sahip sinematografik etkiler barındıran bir dildir.

\section{Sanat ve Tasarım Bağlamında Sinemagrafın Etkinliği}

Sinemagrafın estetik dili, fotoğraf ve sinema-video arasındaki teknik dönüşümden kaynaklanır. Teknik ve estetik dilini oluşturma sürecinde olan sinemagraf fotoğraf ve sinema'nın yaptığı gibi- kendisine yeni mecralar aramak durumundadır. Kevin Burg’a göre teknoloji, bant genişliği ve ekipmanların bir araya gelmesi ile sinemagraf mümkün olur (Warren, Christina, 2011). Sinemagrafın mecrası sayısal iletişim teknolojileridir. İnternet, sosyal ağ ve fotoğraf paylaşım yazılımları ile sanal mecrada estetik dilini yaymak durumundadır.'Film video ve dijital medyanın sanatta kullanımı, sanatın yeni teknoloji ve iletişime verdiği reaksiyonun bir işaretidir. Böylelikle, çağdaş sanat, sanatın her zaman yaptığı şeyi yapar: mevcut koşullara yanıt verir." (Pooke, Whitham, 2013: 146). Sinemagraf, ürettiği fotoğrafik, sinematografik anlam düzeyleri, estetik dili ile teknolojik gelişmelerin (dijital fotoğraf makinesi, sayısal görüntü işleme yazılımları, mobil cihazlar) ve iletişim araçlarının (geniş bant internet, telefon-tablet) gelişiminin sonucudur. Sayısal iletişim teknolojileri yeni biçim ve estetik normları ile çağdaş sanatın alanını genişletmektedir. "Çağdaş sanat, birçoğu daha önce sanatın kapsamının dışında olan ortam ve disiplinleri kucaklar. Dahası, bunların, ayrı bir form olarak kullanılması da gerekmez. Bazı çağdaş sanat eserleri, farklı ortam ve sanatsal disiplinlerin birleştirildiği bir karma pratik kullanır. Bu melezlik, geçmiște sanatsal tür ve pratik olarak tanımlanan kesin sınırların bazılarını ortadan kaldırır" (Pooke, Whitham, 2013: 93). Çağdaş sanatın karma pratiğe dayanan yapısı melez bir form olan sinemagrafın teknik düzeyinde (fotoğraf, sinema-video arasındaki konumu) ve anlam düzeyinde (fotoğrafik ve sinematografik ) görülebilir. Sinemagrafın teknoloji ve iletişim ile ilişkisi, karma pratiğe dayanan melez yapısı ile çağdaş sanatın bir formu olabileceği düşünülebilir. 
Buna rağmen çağdaş sanat formu olarak etkinliği sanat kurumlarının işleyişi, sanatsal ifade olarak kullanımı, sanat izleyicisinin geleneksel görme ve izleme biçimleri, teknik sınırlılıklar; üretim, dağıtım ve sunum ile ilgili gelişimlere bağııdır.

Tasarım bağlamında ele alındığında sinemagraf fotoğraftan farklı olarak bir ekrana ihtiyaç duyar. Bu yönüyle cep telefonları, bilgisayar monitörleri, reklam tabelaları vb. görüntüleme sistemleri sinemagrafın kullanılabileceği mecralar olarak değerlendirilebilir. Jamie Beck ve Kevin Burg'un 2011 yılında Paris moda haftasında ürettiği sinemagraflar moda fotoğrafçılığındaki örnekler olarak öne çıkar (Schiet, 2012: 3). Moda ve portre sinemagrafları incelendiğinde aksesuar ve takı bulunan bölgelerin, elbise, saç ve gözün hareketlendirildiği, hareketli bölgelerin izleyiciyi ürüne yoğunlaştırdığı, görsel bir deneyim yaşattığı gözlemlenebilir. Bunun yanında modelin kişisel özellikleri, yaşam biçimi ile ilgili eşyalar hareket ettirilerek portre sinemagraflarında anlatım etkisi artırılmaktadır (Fot. 6, 7, 8).

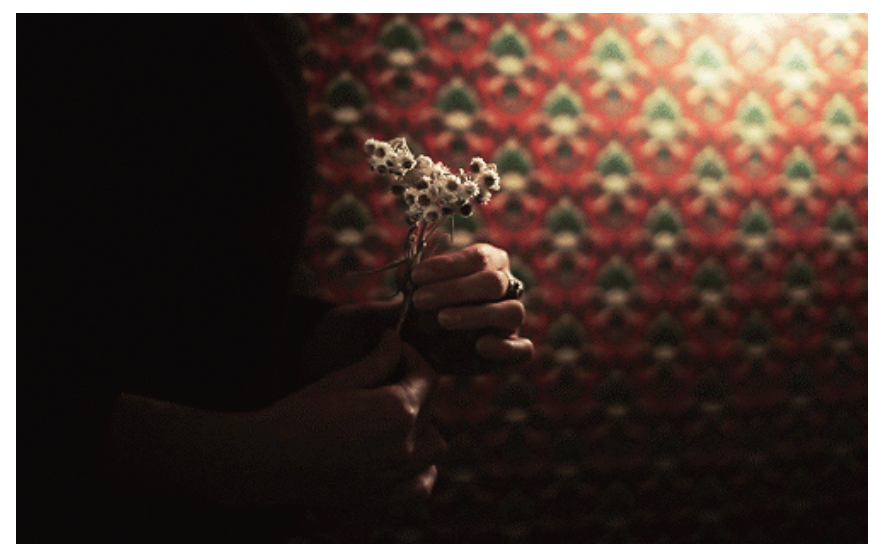

Fot. 6. İsimsiz, Julien Douvier, 2014.

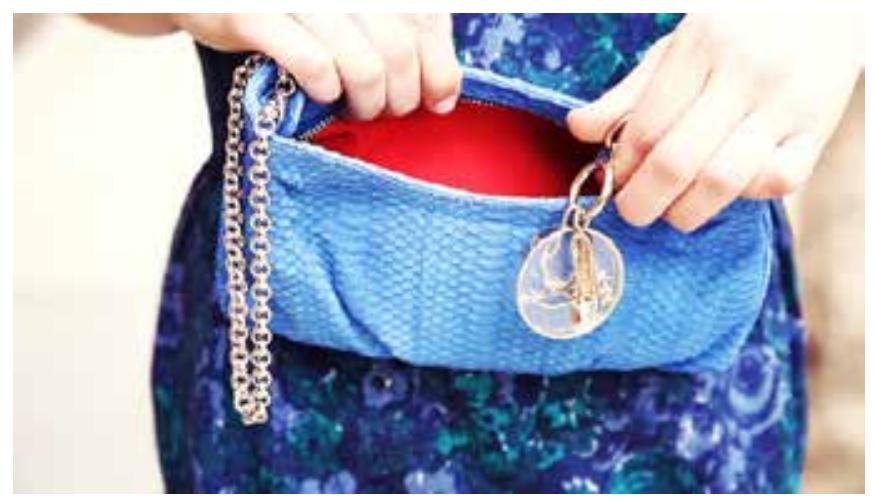

Fot. 7. Louboutin-Medallion, Jamie Beck \& Kevin Burg, 2012.
İçeceğin bardağa dökülmesi, hareketli balon kabarcıkları, yemeği pişiren ateş, üzerinden su damlaları akan domates, yemekten çıkan duman gibi hareketler yiyecek-içecek sinemagraflarının belirgin özellikleridir. Sinemagrafın hareket temsili ile izleyende açlık duygusu uyanmakta, yemek deneyimleri hatırlatılmaktadır. Tenis, futbol vb. sporlarda hareketli bölgeler ile sporun hız-harekete dayanan yapısı temsil edilmektedir. Mimari çekimlerde; insan, duman, ışık, su, perde hareketleri mekanın yaşanabilirliği, canlılı̆ı ve doğallığını gösterebilmektedir. Çekimler ilgili olduğu konuyu fotoğrafik kompozisyonda aktarmasının yanında izleyende sinematografik anlam düzeylerini oluşturmaktadır.
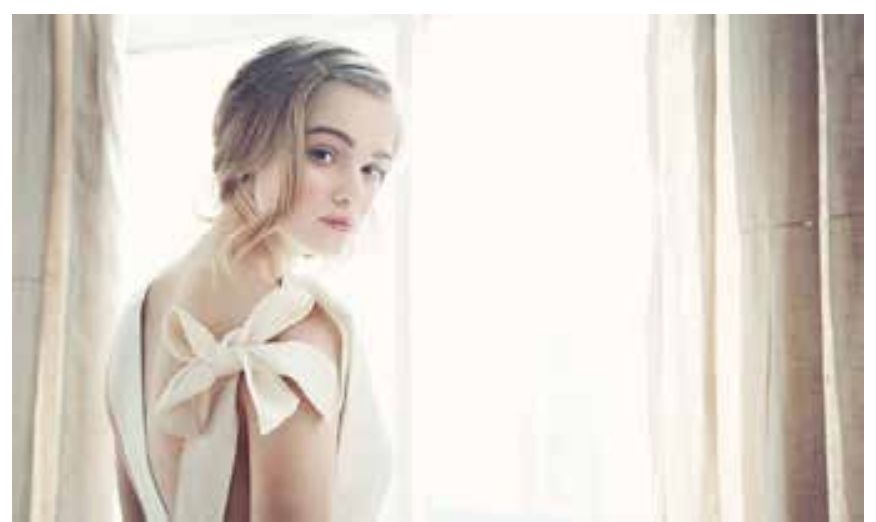

Fot. 8. Ermilio Bow, Jamie Beck \& Kevin Burg, 2012.

Tasarım bağlamında sinemagraf örnekleri incelendiğinde ürettiği görme-izleme biçimi; zaman, hareket, mekan temsilleri ve estetik dilinin görsel tasarımı destekleyen ve biçimlendiren yönleri olduğu görülebilir. Bu yönüyle sinemagraf kitle iletişiminde etkin bir görsel tasarım unsuru olabilecek niteliktedir. Mobil cihazlar kitle iletişimindeki etkinliğinin yanında görsel tasarımlar için üretim, dağıtım ve sunum aracıdır. Türkiye'de 2009 yılı internet abone sayısı 8.849.779 iken 2015 Mart itibari ile bu sayı 42.921.781'dir. Bu sayının yaklaşık 33.844.862 (\%79)'u mobil cepten ve bilgisayardan internet abonesidir (Btik Raporu, 2015). Mobil cihazlarda internet aboneliğinin yaygınlığı; iletişim teknolojilerinin çeşitliliği, bant genişliği ve internet hızlarının yükselmesi ile farklı görsel tasarımlara ihtiyaç duyan kitle iletişim teknolojilerinde sinemagrafın gelişimi ve etkinliği açısından belirleyicidir. 
Örneğin iphone için geliştirilen sinemagram ile kullanıcılar cep telefonları ile sinemagraf üretip paylaşabilmektedir (Niewland, 2012: 21). Kullanıcılar sinemagram yazılımı ile kendi sinemagraflarını üretip, paylaşarak sanal mecrada bir araya gelmekte, trend oluşturabilmektedir. Bu yönüyle kitlenin talep ettiği bir görsel tasarım unsurudur. Öte yandan kitle iletişiminin hızlı döngüsüne uygun biçimde videodaki hareketi otomatik maskeleyen sinemagraf yazılımları mevcuttur (Tompkin, Pece, Subr, Kautz, 2011:1). Üretilen sinemagraflar eğlence, bilgi vb. amaçlarla paylaşılmakta kendi görme-izleme biçimini ve kitlesini oluşturmakta, görsel içerik üretmede yeni bir tasarım unsuru olmaktadır. Haber, eğlence vb. içerik üreten internet siteleri (video önizlemesi vb.), e-ticaret uygulamaları (ürün, hizmet ön izlemesi), e-kitaplar, interaktif mağaza vitrinleri, sinema afişleri (hareketli afiş), akıllı tahta ile yapılan eğitim-öğretim faaliyetleri, reklam panoları, yönlendirme işaret ve levhalarında sinemagrafın görsel tasarımı destekleyeceği düşünülmektedir. Tasarım bağlamında etkinliği analiz edilen sinemagrafın mobil cihazlar ve mobil internetin gelişimi ile kitlelere ulaşmadaki öneminin artacağı belirgindir (Btik Raporu, 2015). Ürettiği fotoğrafik ve sinematografik anlam düzeyleri ile kendi estetiğini oluşturan sinemagrafın yeni bir görsel tasarım unsuru olarak kitle iletişim mecralarında farklı kullanımlara imkan vereceği açıktır.

\section{Sonuç}

Fotoğrafta hareketli görüntü arayışı -öncülü tarihsel örneklerinden farklılaşarak- sayısal teknolojiler sayesinde biçim, içerik ve teknik olarak değişim göstermektedir. Fotoğrafik kompozisyon sinemagrafın hareket temelli estetik dili ile dönüşüme uğramakta, tek karede hareketli görüntüler içeren, dolayısıyla sinematografik etkiye sahip görüntüleri mümkün kılmaktadır.

Sinemagraf fotoğrafik ve sinematografik anlam düzeyleri, hareket temsili, zamansal gerçekliği değiştirmesi, üçüncü boyut temsili, ürettiği görme-izleme biçimi, değişken renk-leke-1şık değerleri, tekniğin estetik dile dönüşümü ile çağdaş sanatın melez pratiğine uygun teknoloji temelli bir tekniktir. Çağdaş sanat formu olarak etkinliği sanat kurum ve pratiklerine; teknik sınırılıklara; estetik diline, üretim, dağıtım ve sunum ile ilgili gelişimlere bağlıdır.

Ürettiği görme-izleme biçimi; zaman, hareket, mekan temsilleri ve estetik dilinin görsel tasarımı destekleyen ve biçimlendiren yönleri ile sinemagraf kitle iletişiminde etkin ve yeni bir görsel tasarım unsuru olarak mobil cihazların artışı ile üretim, dağıtım, sunum ve içerikte gelişim gösterebilecek niteliktedir.

\section{Notlar:}

1- Omniskop: Birbirine benzer iki görüntüye hareket eder izlenimi verebilen optik aygit.

2- Sinematograf: Görüntüleri kaydetmeye ve bir ekran üzerine yansıtmaya yarayan aygit.

\section{Kaynakça}

Berger, John (2005), Görme Biçimleri, çev: Yurdanur Salman, İstanbul: Metis.

Frizot, Michel (Ed.) (1998), 'The Cinematograph', A New History Of Photography, Köln: Könemann.

Mulligan, Therese, Wooters, David. (Ed.), A History of Photography From 1839 To The Present, (1999), Berlin: Taschen Gmbh.

Pooke G., Whitham G., (2013), Çağdaş Sanatı Anlamak, çev.Tufan Göbekçin, İstanbul:Optimist.

Tümay, Sadık, (2010), “Dijitalism”, Bakaç Dergisi, (2010-5)

\section{İnternet Kaynakları}

(Türkiye Elektronik Haberleşme Sektörü, Üç Aylık Pazar Verileri Raporu), Bilgi Teknolojileri Ve İletişim Kurumu, Mayıs 2015, Ankara (2015)

http://www.btk.gov.tr/File/?path=R00T\%2f1\%2fDocument s\%2fSayfalar\%2fPazar_Verileri\%2f2015-Q1.pdf, (01.10.2015)

Manovich, L. Post Media Aesthetics, (2001) http://manovich.net/content/04-projects/032-post-mediaaesthetics/29_article_2001.pdf , (02.10.2015)

Mantel, G. If We Don't, Remember Me, (2012), http://iwdrm. tumblr.com/ (01.12.2014)

Niewland, Meaghan, (2012) Framed In Time: A Cinemagraph Series Of The Everyday \& Grounded Theory Of Cinemagraphy, Communication And New Media Mcmaster University, (01.12.2014)

Schiet, Noraly, (2012) From Muybridge To Cinemagraph: Renewed Interest \& Nostalgia in The Animated Image, Software Studies Master New Media \& Digital Culture, University Of Utrecht (01.04.2014) 
Tompkin James, Pece Fabrizio, Subr Kartic, Kautz Jan, (2011) Towards Moment Imagery: Automatic Cinemagraphs, University College London,

http://vecg.cs.ucl.ac.uk/Projects/AutoCinemagraphs/ autocinemagraphs.pdf,(03.05.2015)

Warren, Christina, (2011) How Tumblr and Cinemagraphs Became the New Web Design Chic. Mashable. Http://mashable. com/2011/12/21/kevin-burg-cinemagraphs-tumblr/ (01.12.2014)

\section{Görsel Kaynaklar}

Fotoğraf 1. https://screenheritage.files.wordpress.com/2007/12/ zoopraxiscope1.jpg, 20.01.2016

Fotoğraf 2. http://annstreetstudio.com/2011/02/12/les-tendrilskaelen/, 20.01.2016

Fotoğraf 3. http://cdn0.dailydot.com/uploaded/imagesoriginal /2012/1/5/ theshining.gif, 20.01.2016

Fotoğraf 4. http://www.thecitrusreport.com/wp-contentuploads /2011/04/newspaper-man-615.gif, 20.01.2016

Fotoğraf 5. http://cinemagraphs.ch/wp-content/uploads/2011

/11/cinemagraph_Out-my-Chelsea-Hotel-window.gif, 20.01.2016

Fotoğraf 6. http://33.media.tumblr.com/1897a14a5f923503cd7 8ced49b443bc0/tumblr_nebkltEDVx1s85u2fo1_500. gif, 20.01.2016

Fotoğraf 7. http://d2436y6oj07al2.cloudfront.net/assetsvbblog /2014/12/louboutin-medallion-429.gif, 20.01.2016

Fotoğraf 8. https://savoiaonline.files.wordpress.com/2012/12/ ermilio-bow-429.gif?w=640\&h=392\&crop=1, 20.01.2016 